\title{
ANALISIS SITIRAN JURNAL PSIKOLOGI UGM TAHUN 1997-2006

\author{
Citation Analysis of Gadjah Mada University Psychology Journal \\ dating from 1997 to 2006.
}

Pergola Irianti*, Sri Rochyanti Zulaikha***

\begin{abstract}
The study aims: (I) to discover the foreign journal referred by the Gadjah Mada University Psychology Journal dating from 1997 to 2006, (2) to know the percentage of use of the subscribed foreign journal by the Faculty Library of Psychology, Gadjah Mada University founded in Gadjah Mada University Psychology Journal from 1997 to 2006, (3) to know the relevancy and use of foreign journal by the scientific article in the Gadjah Mada University Psychology Journal dating from 1997 to 2006, (4) to know the currency of the foreign journal referred by Gadjah Mada University Psychology Journal dating from 1997 to 2006. The study is a descriptive research with the Gadjah Mada University Psychology Journal by 1997-2006 as a subject, and the foreign journals referred in Gadjah Mada University Psychology Journal by 1997-2006 as an object. Documentation, and interview are used as methods of collecting data, and citation analysis as an data analysis. The result of study: (1) There are 148 titles of foreign journal cited in Gadjah Mada University Journal of Psychology dating from 1997-2006, including 14 titles of the journal subscribed by Faculty Library of Gadjah Mada University, (2) The frequence of the citation of the 14 titles was that: Journal of Personality and Social Psychology by 68 times (39,76\%), Journal of Consulting and Clinical Psychology by 23 (13,45\%), Journal of Applied Psychology by 21 (12,28\%), Psychological Bulletin by 11 (6,43\%), Journal of Abnormal Psychology and Journal of Counseling Psychology by 9 respectively (5,26\%), Journal of Educational Psychology by 8(4,67\%), Developmental Psychology by 7(4,09\%), Journal of Occupational Psychology by 5 (2,92\%), Journal of Cross Cultural Psychology and Psychological Review by 3 respectively (1,75\%), Journal of Experimental Psychology by 2 (1,16\%), American Psychologist and Health Psychology by 1 each $(0,58 \%)$. (3) The re are also a relevancy between the scientific article and the foreign journal referred, in the Gadjah Mada University Psychology Journal dating from 1997 to 2006 (4) The foreign journal subscribed by the Faculty Library of Psychology Gadjah Mada University was included in a current category (52,77\%), not current category $(45,47 \%)$, and more than 30 years $(1,76 \%)$.
\end{abstract}

Key words: use of journal, citation analysis

\section{ABSTRAK}

Penelitian in bertujuan: (I) menemukan jurnal luar negeri yang disitir oleh jurnal psikologi UGM tahun 1997sampai 2006, (2) mengetahui prosentase peng gunaan jurnal luar negeri yang dilanggan oleh perpustakaan fakultas Psikologi, Universitas Gadjah Mada yang ditemukan di Jurnal Psikologi UGM dari tahun 1997 sampai 2006, (3) mengetahui relevansi dan penggunaan jurnal luar negeri dalam artikel ilmiah di jurnal Psikologi UGM tahun 1997 sampai 2006, (4) mengetahui situasi terbaru jurnal luar negeri yang disitir dalam Jurnal Psikologi UGM tahun 1997 sampai 2006. Studi ini merupakan penelitian deskriptif dengan mengambil jurnal Psikologi UGM tahun 1997- 2006 sebagai subjek penelitian, dan jurnal luar negeri yang disitir dalam jurnal Psikologi UGM tahun 1997-2006 sebagai objek penelitian. Metode yang digunakan dalam pengumpulan data adalah metode dokumentasi dan wawancara, sedangkan analisis sitiran digunakan sebagai analisis data. Penelitian ini menghasilkan: (I) Terdapat 148 judul jurnal luar negeri yang disitir dalam jurnal Psikologi UGM tahun 1997-2006, termasuk 14 judul jurnal yang dilanggan oleh perpustakaan fakultas Psikologi UGM, (2) Frekuensi sitasi dari 14 judul tersebut adalah: Journal of Personatity and Social Psychology sebanyak 68 kali (39,76\%), Journal of Consulting and Clinical Psychology sebanyak 23(13,45\%), Journal of Applied Psychology sebanyak 21 (12,28\%), Psychological Bulletin sebanyak $I I(6,43 \%)$, Journal of Abnormal Psychology and Journal of Counseling Psychology sebanyak 9 (5,26\%), Journal of Educational Psychology sebanyak $8(4,67 \%)$, Developmental Psychology sebanyak $7(4,09 \%)$, Journal of Occupational Psychology sebanyak 5 (2,92\%), Journal of Cross Cultural Psychology and Psychological Review sebanyak 3 (1,75\%), Journal of Experimental Psychology sebanyak 2 (1,16\%), American Psychologist and Health Psychology sebanyak I setiap jurnal (0,58\%). (3) Juga ada relevansi antara artikel ilmiah dan jurnal luar negeri yang disitir dalam jurnal Psikologi UGM tahun 1997 sampia 2006 (4) Jurnal luar negeri yang dilanggan oleh perpustakaan fakultas Psikologi UGM termasuk dalam kategori terbaru (52,77\%), tidak dalam kategori terbaru $(45,47 \%)$, dan lebih dari 30 tahun $(1,76 \%)$.

Kata kunci: penggunaan jurnal, analisis sitiran

* Perpustakaan Universitas Gadjah Mada, Yogyakarta

** Fakultas Adab UIN Sunan Kalijaga Yogyakarta 


\section{PENDAHULUAN}

Pada dasarnya perpustakaan mengemban lima fungsi, dan salah satu di antaranya adalah fungsi penelitian (Septiyantono, 2003:15-17). Fungsi penelitian dalam hal ini koleksi perpustakaan dimanfaatkan peneliti untuk memenuhi kebutuhan literatur penelitian yang sedang atau akan dilakukan.

Perpustakaan perguruan tinggi sebagai sarana penunjang program pendidikan, penelitian, dan pengabdian kepada masyarakat, maka koleksi perpustakaan di samping buku teks sebagai koleksi utama perlu disediakan pula koleksi hasil-hasil penelitian dan jurnal. Jurnal sangat membantu para peneliti dalam pelaksanaan penelitiannya, karena muatan informasinya berupa karya-karya ilmiah atau hasil-hasil penelitian terbaru.

Penerbitan jurnal dalam segala bidang ilmu pengetabuan di negara berkembang seperti Indonesia masih sangat terbatas. Dikemukakan oleh Kurniawan (2005), bahwa publikasi ilmiah di negara Indonesia masih rendah. Berdasarkan data publikasi yang diterbitkan tahun 1992-2002, hasil riset ilmiah Indonesia masih berada di peringkat bawah (Harjono, 2006).

Rendahnya publikasi ilmiah terbitan dalam negeri termasuk publikasi jurnal di satu sisi, dan kebutuhan perpustakaan perguruan tinggi untuk melengkapi diri dengan koleksi jurnal di sisi lain, menuntut perpustakaan melanggan publikasi jurnal terbitan luar negeri sesuai dengan bidang disiplin ilmu yang diselenggarakan. Demikian halnya dengan Perpustakaan Fakultas Psikologi UGM, utamanya dalam penyediaan koleksi jurnal, maka sejak tahun 1977 hingga saat ini telah melanggan beberapa judul jurnal luar negeri. Namun dalam perjalanannya dari tahun ke tahun selalu mengalami perubahan karena harga langganan yang semakin mahal sementara besarnya dana yang tersedia sangat terbatas, sehingga harus ada beberapa judul jurnal yang dihentikan pengadaannya.

Idealnya penentuan keberlanjutan dan pemberhentian pengadaan jurnal yang telah dilanggan selain pertimbangan dana, perlu diperhatikan juga pemanfaatannya oleh pengguna, oleh karena itu perlu dilakukan evaluasi. Evaluasi koleksi adalah kegiatan menilai koleksi perpustakaan baik dari segi ketersediaan koleksi bagi pengguna maupun pemanfaatan koleksi oleh pengguna (Sujana, 2006). Ada dua metode yang dapat dilakukan untuk melakukan evaluasi koleksi, yaitu metode terpusat pada koleksi, dan metode terpusat pada pemanfaatan koleksi. Salah satu cara evaluasi dengan metode terpusat pada pemanfaatan koleksi dapat dilakukan menggunakan cara analisis sitiran (Evans, 2000:434).

Pada perpustakaan perguruan tinggi, maka evaluasi dengan cara analisis sitiran dapat dilakukan dengan mengidentifikasi semua pustaka yang tercantum dalam daftar pustaka produk ilmiah (skripsi, tesis, disertasi) maupun publikasi ilmiah (jurnal) lembaga induk perpustakaan (Evans, 2000:445).

Salah satu produk ilmiah terbitan Fakultas Psikologi Universitas Gadjah Mada adalah Jurnal Psikologi UGM yang memuat artikel ilmiah atau ringkasan hasil penelitian dosen maupun mahasiswa (skripsi, tesis, disertasi).

Berdasarkan uraian di atas, peneliti berasumsi bahwa untuk mengevaluasi pemanfaatan koleksi jurnal terbitan luar negeri yang pernah dilanggan (baik yang sudah berhenti maupun masih dilanggan) oleh Perpustakaan Fakultas Psikologi Universitas Gadjah Mada, dapat dilakukan dengan menggunakan metode sitiran pada daftar pustaka artikel yang dimuat Jurnal Psikologi UGM.

Berdasarkan asumsi di atas, peneliti merumuskan masalah penelitian sebagai berikut: 
1. Apa sajakah jurnal terbitan luar negeri yang dimanfaatkan dalam artikel Jurnal Psikologi UGM tahun 1997-2006?

2. Berapa persentase pemanfaatan masing-masing jurnal terbitan luar negeri yang pemah dilanggan (baik yang sudah berhenti maupun masih dilanggan) oleh Perpustakaan Fakultas Psikologi Universitas Gadjah Mada dalam artikel Jurnal Psikologi UGM tahun 1997-2006?

3. Adakah relevansi antara kajian pada masing-masing jurnal terbitan luar negeri yang pernah dilanggan (baik yang sudah berhenti maupun masih dilanggan) oleh Perpustakaan Fakultas Psikologi UGM dengan topik artikel yang dimuat dalam Jurnal Psikologi UGM tahun 1997-2006, dan apa manfaatnya dalam artikel yang menyitirnya.

4. Bagaimana kemutakhiran jurnal terbitan luar negeri yang dimanfaatkan dalam artikel Jurnal Psikologi UGM tahun 1997-2006?

Berdasarkan rumusan masalah di atas, penelitian difokuskan pada: (1) judul jurnal terbitan luar negeri (sumber tercetak maupun website) yang dimanfaatkan (disitir dan tercantum) dalam daftar pustaka artikel Jurnal Psikologi UGM tahun 19972006, (2) persentase jurnal terbitan luar negeri yang dimanfaatkan (disitir dan tercantum) pada daftar pustaka artikel Jurnal Psikologi UGM tahun 1997 2006, berdasarkan kelompok judul jumal yang pemah dilanggan (baik sudah berhenti maupun masih dilanggan) Perpustakaan Fakultas Psikologi Universitas Gadjah Mada, (3) Relevansi antara kajian jurnal terbitan luar negeri dengan artikel ilmiah yang menyitir serta pemanfaatannya, (4) kemutakhiran jurnal terbitan luar negeri yang dimanfaatkan (disitir dan tercantum) pada daftar pustaka artikel Jurnal Psikologi UGM 1997-2006.

\section{LANDASAN TEORI}

\section{A. Jurnal}

Istilah jurnal berasal dari bahasa Perancis journal yang berarti catatan harian. Dalam perkembangannya jurnal diartikan sebagai terbitan berkala yang pada umumnya berisi ringkasan laporan penelitian terbaru serta tulisan-tulisan ilmiah yang lain (Lasa, 1998:70). Sedangkan menurut Lembaga Ilmu Pengetahuan Indonesia (LIPI, 1983) jurnal adalah majalah yang memuat informasi mengenai hasil kegiatan di bidang ilmu pengetahuan dan teknologi. Di dalam majalah ini berisi kumpulan pengetahuan baru, pengamatan empiris dan pengembangan gagasan atau usulan. Juga dijelaskan bahwa publikasi ini berfungsi sebagai media komunikasi yang sangat penting dalam ilmu pengetahuan karena memuat informasi terbaru. Bagi para ilmuwan, media ini dapat dipergunakan sebagai sarana untuk mengikuti perkembangan ilmu pengetahuan dan teknologi dalam bidangnya, dan sekaligus se bagai wadah bagi mereka untuk melaporkan hasil penemuan serta buah pikirannya. Sementara itu menurut Sulistyo-Basuki (2002), jurnal merupakan: (a) media paling penting dalam komunikasi ilmiah, (b) merupakan pengetahuan publik, dan (c) arsip umum yang dapat dibaca oleh siapa saja.

Sebagian besar publikasi jenis ini diterbitkan oleh lembaga pendidikan maupun lembaga penelitian, dan akhir-akhir ini penerbit komersial juga telah banyak yang mengelolanya. Agar kualitas tetap terjaga dengan baik, maka terbitan ini biasanya mempunyai editor atau kelompok orang yang memang ahli di bidangnya (Saleh \& Toha, 1996:11).

Menurut Prawitasari (2005:23) jurnal bermanfaat untuk mengetahui perkembangan terkini suatu ilmu pengetahuan, yaitu dengan menyimak tulisan-tulisan hasil penelitian empiris yang diterbitkan dalam publikasi tersebut. Jurnal yang baik mempunyai mitra bestari (beberapa ahli sesuai bidang kajian jurnal) 
dan penilaian sejawat yang merupakan wakil dari masyarakat ilmiah. Adanya mitra bestari menunjukkan bahwa pemaparan hasil penelitian dalam sebuah jurnal telah dinilai kelayakannya oleh sejawat dan mitra bestari tersebut. Dengan demikian khalayak ramai dapat mengikutinya dan menjaga supaya tidak mudah terjadi plagiat.

Menurut Rousseau (2002:420-421) ada beberapa ciri yang dapat menunjukkan kualitas suatu jurnal, yaitu: (a) tulisan atau artikel yang dimuat harus memenuhi standar (hasil penelitian terbaru, reliabilitas metode, kontrol yang kuat, dan penggunaan data statistik), (b) memiliki editor yang qualified, (c) publikasinya cepat, (d) dilengkapi dengan abstrak dan indeks, (e) para ilmuwan memiliki kepercayaan tinggi terhadap artikel-artikel yang diterbitkan dalam jurnal, (f) memiliki frekuensi yang tinggi dalam merujuk jumal yang lain, (g) ada abstrak atau ringkasan dalam bahasa Inggris, (h) ada identitas pengarang, (i) disertai informasi bibliografi yang lengkap.

Berdasarkan uraian di atas dapat disimpulkan bahwa jumal merupakan salah satu media komunikasi ilmiah dengan waktu terbit lebih cepat dan teratur. Jurnal bermanfaat untuk mengetahui perkembangan terkini suatu ilmu pengetahuan berdasarkan artikel ilmiah yang dipublikasikannya. Ciri penting yang dapat menunjukkan kualitas sebuah jurnal adalah adanya editor ahli sesuai bidangnya, dan nama editor tercantum pada bagian editorial board setiap terbitannya (http:/ len.wikipedia.org/wiki/Editorial board). Para editor inilah yang akan menentukan kelayakan sebuah artikel diterbitkan dalam sebuah jurnal. Penerbitan artikel ilmiah tersebut harus menyertakan daftar pustaka yang telah dimanfaatkan sebagai acuan.

\section{B. Pemanfaatan jurnal}

Di dalam Bahasa Indonesia, pemanfaatan berasal dari kata dasar "manfaat". Arti kata manfaat sama dengan guna atau faedah. Pemanfaatan merupakan proses, cara, atau perbuatan memanfaatkan (Kamus Besar Bahasa Indonesia, 1988:555). Jika seorang penulis merujuk artikel lain yang telah terbit sebelumnya, dapat diartikan bahwa yang dirujuknya bermanfaat bagi karya tulisnya (Soehardjan, 1995:40). Keberhasilan penelitian dan pengkajian yang dilakukan oleh sivitas akademika atau para peneliti ditentukan oleh pemanfaatan dan dukungan koleksi perpustakaan lembaga pendidikan tinggi atau lembaga penelitian tersebut (Mansjur, 2005:32). Istilah pemanfaatan di sini dimaksudkan bahwa koleksi yang ada di perpustakaan digunakan peneliti sebagai rujukan atau acuan penelitian.

Karya yang dirujuk oleh peneliti dalam menyusun hasil penelitiannya dilakukan setelah karya yang dirujuk diterbitkan (Andriani, 2002:29). Berdasarkan uraian di atas, pemanfaatan jumal dalam penelitian ini adalah penggunaan jurnal untuk kepentingan penulisan artikel ilmiah yang dapat dibuktikan dengan dicantumkannya jurnal tersebut pada daftar pustaka, atau dengan kata lain disitir dan tercantum pada daftar pustaka artikel ilmiah.

\section{Analisis Sitiran}

Pada dasarnya analisis sitiran merupakan bagian dari bibliometrika. The British Standards Institution, mendefinisikan bibliometrika (bibliometrics) sebagai kajian penggunaan dokumen dan pola publikasi dengan menerapkan metode matematika dan statistika. Dalam definisi ini metode matematika dan statistika dapat diterapkan dalam segala bentuk media komunikasi yang telah direkam secara luas, baik berupa grafis maupun elektronis. Bibliometrika terbagi atas dua kelompok besar yaitu kelompok yang mengkaji distribusi publikasi dan kelompok yang mengkaji analisis sitiran (SulistyoBasuki, 2002). 
Menurut Andriani (2002:29) sitiran adalah pernyataan yang diterima suatu dokumen dari dokumen lain, dalam hal ini sitiran mengarah pada karya yang diacu dan dilakukan oleh penulis setelah karya yang diacu diterbitkan. Selanjutnya karya yang diacu (sumber acuan) harus dicantumkan dalam daftar pustaka dokumen.

Dengan kata lain sitiran adalah dokumen (buku, majalah, dan jenis lain) yang dipergunakan sebagai rujukan sebuah karya, penelitian atau tulisan ilmiah, dan dicantumkan dalam daftar pustaka karya tersebut. Dengan demikian suatu karya ilmiah tidak dapat berdiri sendiri, melainkan saling terkait dengan literatur sebelumnya.

Ada beberapa alasan mengapa para ilmuwan selalu menyitir berbagai macam literatur dalam rangka penulisan karya mereka. Garfield (dalam Hartinah, 2002) mengemukakan bahwa seorang penulis menyitir penulis lain karena: (1) Memberikan penghormatan kepada penulis atau karya di bidangnya. (2) Mengidentifikasi metodologi atau pendekatan teori. (3) Memberi latar belakang atau bacaan bagi mereka yang ingin mengetahui lebih lanjut topik yang sudah ditulis. (4) Mengoreksi karya sendiri atau karya orang lain. (5) Memberikan kritik terhadap karya yang telah terbit sebelumnya. (6) Memperkuat klaim suatu temuan. (7) Sebagai panduan bagi penulis lain yang akan mendalami topik tulisan yang disitir.

Sedangkan menurut Sulistyo-Basuki (1994: 176-177), seorang penulis yang menyitir karya orang lain dan mencantumkannya pada daftar pustaka, bertujuan untuk: (1) Memberikan penghargaan terhadap karya sebelumnya. (2) Memberikan penghormatan pada karya yang berkaitan. (3) Mengidentifikasi metodologi, angka dan sebagainya. (4) Memberikan bahan bacaan sebagai latar belakang. (5) Mengkoreksi karya orang lain. (6) Mengkoreksi karya sendiri. (7) Mengkritik karya sebelumnya. (8) Mendukung klaim sebuah penemuan. (9) Memberitahu peneliti tentang karya yang akan terbit. (10) Memberikan arahan pada karya yang tidak tersebar, tidak tercakup dalam majalah indeks, atau karya yang tidak pernah dirujuk oleh pengarang lain. (11) Memberi otentifikasi tentang data dan kelompok fakta. (12) Mengidentifikasi publikasi asli tempat sebuah ide atau gagasan dibahas. (13) Mempublikasikan karya atau gagasan orang lain. (14) Menyangkal klaim yang diajukan oleh pengarang lain. (15) Mengidentifkasi publikasi orisinal yang memeriksa sebuah istilah, seperti Paretos Law, Friedel-Crafy Reaction.

Analisis sitiran adalah kajian terhadap sejumlah sitiran atau rujukan yang terdapat dalam karya tulis ilmiah tertentu (Zulaikha, 2002:41). Sedangkan menurut Hartinah (2002) analisis sitiran adalah penyelidikan melalui data sitiran dari suatu dokumen, baik dokumen yang disitir maupun dokumen yang menyitir. Adapun hal-hal yang diselidiki antara lain: pengarang, subjek, tahun terbit, dan sumber dokumen (jurnal, buku, dan jenis lain). Menurut Sulistyo-Basuki (1994:177), analisis sitiran adalah analisis pada kepustakaan. Pada awalnya kajian berupa frekuensi sitiran, bahasa, tahun, jenis terbitan, dan pada saat ini berkembang pada kajian terhadap hubungan antara satu majalah dengan majalah lainnya, kajian terhadap ukuran sentralitas antara satu majalah dengan majalah lain, penelitian paro hidup bidang ilmu serta jaringan yang terbentuk akibat sitiran.

Menurut Hartinah (2002) kajian bibliometrika menggunakan analisis sitiran merupakan cara untuk menentukan berbagai kepentingan, antara lain: (1) Evaluasi program riset. (2) Pemetaan ilmu pengetahuan. (3) Visualisasi suatu disiplin ilmu. (4) Indikator ilmu pengetahuan dan teknologi. (5) Faktor dampak dari suatu majalah (Journal Impact factor). (6) Kualitas suatu majalah. (7) Pengembangan koleksi majalah, dan lain-lain. 
Menurut Smith (dalam Zulaikha, 2002:43) analisis sitiran dapat diterapkan dalam berbagai bidang kajian, antara lain: (1) Kajian literatur, dalam hal ini sitiran dilihat dalam bidang subjek tertentu untuk menggambarkan pola sitiran. (2) Kajian jenis literatur, kajian ini dapat dipakai untuk mengukur penyebaran hasil-hasil yang dilaporkan dalam jenis literatur tertentu. (3) Kajian pemakai, analisis sitiran mempunyai implikasi untuk pengembangan koleksi dan merancang pelayanan yang berorientasi kepada pemakai. (4) Kajian historis, dapat digunakan untuk menjajaki kronologi dari kejadian-kejadian yang ada, hubunganhubungan di antara kejadian tersebut. (5) Pola komunikasi, analisis sitiran dapat digunakan untuk mengidentifikasi masalah-masalah dalam komunikasi. (6) Evaluasi bibliometrika, dalam hal ini analisis sitiran didefinisikan sebagai evaluasi dan interpretasi dari sitiran-sitiran yang diterima oleh artikel, ilmuwan, universitas, negara dan sejumlah kegiatan ilmiah lainnya. (7) Pengembangan koleksi

Menurut Langlois dan Schulz (dalam Margono, 2000:54-59) evaluasi pemakaian jumal dapat dilakukan menggunakan metode analisis sitiran terhadap artikel jurnal bidang tertentu. Evaluasi bermanfaat untuk keperluan pengadaan majalah dan penentuan judul majalah yang benar-benar dibutuhkan dan dipakai oleh pengguna.

Ada beberapa manfaat yang dapat diperoleh dengan kajian analisis sitiran. Menurut Budd (1990:85) dikemukakan bahwa metode analisis sitiran dapat dipergunakan untuk mengukur komunikasi ilmiah dalam disiplin ilmu tertentu. Dengan metode ini dapat diidentifikasi karakteristik dokumen yang dipergunakan dalam penelitian di perguruan tinggi (seperti jurnal, buku dan jenis lain), usia literatur, dan subjek yang sering dirujuk. Sementara itu Sylvia (1998) berpendapat bahwa analisis sitiran merupak an metode efektif, namun kadang terabaikan dalam hal pengembangan dan evaluasi koleksi. Pada dasarnya metode ini adalah menghitung dan meranking jumlah dokumen dirujuk baik dalam bibliografi maupun catatan kaki, dan sebagai alat pengindeksan.

Kajian bibliometrika dalam hal ini analisis sitiran memberi sumbangan yang tidak sedikit pada bidang Pusdokinfo, baik secara praktis maupun secara teoritis. Manfaat secara praktis antara lain dalam manajemen koleksi perpustakaan, sosiologi ilmu, dan temu kembali informasi. Di dalam manajemen dan pembinaan koleksi dengan metode analisis sitiran dapat diketahui pertumbuhan literatur, penentuan jurnal inti (core journal) maupun buku inti (core book) suatu perpustakaan. Manfaat secara teoritis adalah sebagai pengembangan ilmu informasi dan perpustakaan. Semakin banyak penelitian menggunakan kajian bibliometrika dengan berbagai aspek kajian maupun bidang ilmu yang berbeda, akan semakin memperkaya jumlah penelitian yang dihasilkan (Septiyantono, 1997:12)

Sedangkan menurut Ching dan Chennupati (2002:398-405) metode analisis sitiran merupakan salah satu dari beberapa metode yang dapat dipergunakan untuk evaluasi koleksi. Dengan metode ini dapat diketahui tingkat keterpakaian koleksi baik buku maupun jurnal, di samping itu dapat diketahui pula mengenai usia publikasi yang dipergunakan sebagai rujukan.

Sebenarnya kajian dengan metode analisis sitiran sangat sederhana dan mudah dilakukan, namun dalam pelaksanaannya diperlukan ketekunan dan ketelitian agar diperoleh hasil yang akurat. Beberapa penelitian pernah dilakukan Cole \& Cole serta Bush (dalam Yulia, 1995:23-24). Penelitian yang dilakukan oleh Cole \& Cole diperoleh hasil bahwa data sitiran berkorelasi tinggi dengan data survai dalam menentukan kualitas sebuah karya ilmuwan. Sedangkan temuan lain dikemukakan oleh Bush, 
bahwa sitiran dari jurnal bidang ekonomi dengan suatu kajian menggunakan pendapat ahli untuk memperoleh peringkat yang serupa, hasilnya menunjukkan bahwa kedua peringkat terșebut mirip sekali. Sementara itu Holmes dan Oppenheim (2001:5) dari Departemen Ilmu Informasi Universitas Loughborough, juga mengungkapkan bahwa kajian manajemen informasi dan perpustakaan di Departemen Pendidikan Inggris yang menggunakan metode analisis sitiran, hasilnya berkorelasi kuat dengan kajian yang menggunakan metode Research Assessment Exercise (RAE) 2001.

Berdasarkan uraian di atas dapat disimpulkan bahwa analisis sitiran memberi manfaat besar dalam pengembangan ilmu pengetahuan, dimana hasil kajian menggunakan metode analisis sitiran dapat disejajarkan dengan hasil kajian menggunakan metode yang lain.

\section{Kemutakhiran Literatur}

Pada dasarnya kemutakhiran literatur yang dirujuk da lam suatu karya tulis ilmiah mencerminkan kekinian (actuality) informasi dari karya tulis tersebut (Hermanto, 2002:1). Menurut Instrumen Evaluasi untuk Akreditasi Berkala Ilmiah 2001, yang dikeluarkan oleh Direktorat Pembinaan Penelitian dan Pengabdian pada Masyarakat-Direktorat Jendral Pendidikan Tinggi (2001), diisyaratkan bahwa kemutakhiran referensi (pustaka acuan) merupakan salah satu aspek substansial yang dinilai dalam pengakreditasian jurnal ilmiah nasional. Dalam instumen ini ditegaskan bahwa kemutakhiran referensi tersebut dengan melihat proporsi terbitan sepuluh tahun terakhir.

Meskipun demikian kualitas sebuah karya ilmiah atau penelitian tidak terkait langsung dengan kemutakhiran literatur yang dirujuk, namun literaturliteratur terbaru yang digunakan sebagai rujukan diharapkan akan membuka cakrawala baru dalam pembahasan hasil penelitian. Dengan demikian penggunaan literatur yang sudah tidak mutakhir (out of date) sebagai rujukan dapat diterima sepanjang data atau informasi yang dimiliki relevan dengan topik artikel, atau belum ada literatur baru yang lebih baik atau lebih lengkap dari literatur tersebut (Hermanto, 2004:3).

Menurut Mikkailov (dalam Herlina, 1995:36), penggunaan literatur yang relatif tidak mutakhir sebagai rujukan dikarenakan adanya kekhususan informasi, misalnya mengenai publikasi orisinil yang menjadi syarat konsep atau ide serta metodologi.

\section{METODE PENELITIAN}

Menurut Irwanto (2004:24) metode penelitian adalah bagian dimana peneliti diminta untuk menjelaskan bagaimana persoalan diteliti. Sedangkan menurut Koentjaraningrat (1994:7) pengertian metode penelitian adalah suatu cara atau jalan dalam suatu penelitian untuk memahami objek yang menjadi sasaran dalam penelitian.

Suryabrata (2003:72) mengemukakan bahwa metode yang digunakan dalam sebuah penelitian harus sesuai dengan rancangan penelitian. Oleh karena itu berdasarkan rancangan penelitian, maka metode penelitian dapat dibedakan menjadi: (a) penelitian historis, (b) penelitian deskriptif, (c) penelitian perkembangan, (d) penelitian kasus dan penelitian lapangan, (e) penelitian korelasional, (f) penelitian kausal komparatif, (g) penelitian eksperimental sungguhan, (h) penelitian eksperimental semu, dan (i) penelitian tindakan.

Penelitian deskriptif bertujuan untuk melakukan analisis hanya sampai pada taraf deskriptif yaitu menganalisis dan menyajikan fakta secara sistematis sehingga mudah dipahami dan disimpulkan (Azwar, 1998:6). 
Penelitian ini merupakan penelitian deskriptif, dengan maksud untuk mengetahui jurnal terbitan luar negeri yang dimanfaatkan (disitir), persentase pemanfaatan jurnal terbitan luar negeri pernah dilanggan, dan usia jurnal terbitan luar negeri yang disitir pada Jurnal Psikologi UGM tahun 1997-2006.

Dalam penelitian sosial, populasi didefinisikan sebagai kelompok subjek yang hendak dikenai generalisasi hasil penelitian. Sebagai suatu populasi, kelompok subjek ini harus memiliki ciri-ciri atau karakteristik-karakteristik bersama yang membedakannya dari kelompok subjek yang lain (Azwar, 2003:77-78).

Menurut Hadi (1975:220) populasi adalah semua wilayah, individu, objek gejala atau peristiwa untuk mana generalisasi atau kesimpulan akan dikenakan. Sedangkan menurut Arikunto (2006:130) populasi adalah keseluruhan subjek penelitian. Apabila peneliti ingin meneliti semua elemen yang ada dalam wilayah penelitian, maka penelitiannya merupakan penelitian populasi.

Populasi atau subjek penelitian ini adalah Jurnal Psikologi UGM tahun 1997 - 2006. Selain keterbatasan waktu dan dana, alasan pembatasan hanya pada Jurnal Psikologi UGM tahun 1997-2006.

Objek penelitian adalah apa yang menjadi titik perhatian suatu penelitian (Arikunto, 2006:118). Pada penelitian ini yang menjadi titik perhatian atau sebagai objek penelitian adalah jurnal terbitan luar negeri yang disitir dan tercantum dalam daftar pustaka artikel Jurnal Psikologi UGM tahun 1997 - 2006.

\section{A. Metode Pengumpulan Data}

Metode pengumpulan data merupakan cara yang digunakan untuk memperoleh data. Metode pengumpulan data ada bermacam-macam antara lain: wawancara, observasi, kuesioner, dan dokumentasi, yang kesemuanya merupakan sebagian dari metode pengumpulan data (Arikunto, 2006:149).

Metode dokumentasi, yaitu cara memperoleh data yang bersumber pada dokumen atau tulisan (Arikunto, 2006:158). Sedangkan metode wawancara menurut Arikunto (2006:227), adalah pengumpulan data dengan cara dialog yang dilakukan oleh pewawancara (interviewer) untuk memperoleh informasi langsung dari terwawancara (interviewee).

Pada penelitian ini ada dua metode pengumpulan data yang dipergunakan, yaitu metode dokumentasi dan metode wawancara. Metode dokumentasi, karena pada penelitian ini data diperoleh dari daftar pustaka atau sitiran dalam artikel ilmiah yang dimuat pada Jurnal Pikologi UGM tahun 19972006. Selanjutnya metode wawancara dipergunakan sebagai bahan pendukung check dan re-check terhadap pemanfaatan jurnal terbitan luar negeri.

\section{B. Metode Analisis Data}

Setelah data terkumpul kemudian peneliti melakukan kegiatan analisis data dengan cara tabulasi frekuensi kemudian dianalisis berdasarkan persentase. Semua perhitungan persentase menggunakan rumus dari Kerlinger (1990:246).

\section{HASIL PENELITIAN \& PEMBaHASAN}

Penelitian ini dilakukan di Perpustakaan Fakultas Psikologi UGM. Berdasarkan analisis data diperoleh hasil bahwa ada 148 judul jurnal terbitan luar negeri yang telah dimanfaatkan atau disitir dalam artikel Jurnal Psikologi UGM tahun 1997-2006. Berikut ini adalah data judul terbitan luar negeri yang dimanfaatkan dalam artikel Jurnal Psikologi UGM 1997-2006. :

1. Academy Management Review

2. Academy of Management Journal

3. Academy of Management Review

4. Addic Behavior

5. Administrative Science Quarterly 
6. Advance in Experimental Social Psychology 7. Advances in Clinical Psychology ...

8. Aggressive Behavior

9. American Educational Research Journal

10. American Journal of Psychology

11. American Journal of Psychotherapy

12. American Journal of Public Health

13. Amcrican Journal of Sociolog

14. American Psychological Society

15. American Psychologist

16. American Sociological Review

17. Annual Review Psychology

18. Applied and Preventive Psychology

19. Archives of General Psychiatry

20. Asian Journal of Social Psychology

21. Basic and Applied Social Psychology

22. Behavior Research Methods, ...

23. Brain Journal of Biological Psychiatry

24. British Journal of Addiction

25. British Journal of Industrial Relation

26. British Journal of Social Psychology

27. British Joural of Psychiatry

28. Business Review

29. Canadian Medical Association Journal

30. Canadian Military Journal

31. Child Development

32. Clinical Psychology Review

33. Clinical psychology: ...

34. Cognitive Psychology

35. Cogniton and Emotion

36. Culture and Psychology

37. Cyber Psychology and Behavior

38. Death Studies

39. Developmental Psychology

40. Drug Abuse Prevention Research and ...

41. Early Childhood Research Quarterly

42. Educational Gerontology

43. Educational Research Journal

44. Educatonal Technology

45. European Journal of Personality

46. Family Planning \& Perpective

47. Group and Organization Studies

48. Health Psychology

49. Human Communication Research

50. Human Development

51. Humant Relations

52. Humor

53. Intercultural Education

54. International Journal of Psychology

55. Journal Antropology Quarterly

56. Journal for Research in Mathematics..

57. Journal for the Theory of Social Behaviours

58. Journal Hospilal and Community

59. Journal of Abnormal Child Pscyhology

60. Journal of Abnormal Psychology

61. Journal of Administrative Science

62. Journal of Adolescent Research

63. Journal of Applied Philosophy

64. Journal of Applied Psychology

65. Journal of Children in Contemporary Society

66. Journal of Community Psychology

67. Journal of Community, Work and Family

68. Journal of Computer Assissted Learning

69. Journal of Consulting and Clinical Psychology

70. Journal of Counseling and Development

71. Journal of Counseling Psychotogy

72. Journal of Cross-Cultural Psychology

73. Journal of Developmental Psychology

74. Journal of Drug Education

75. Journal of Drug Issues

76. Journal of Educational Psychology

77. Journal of Experimental Psychology

78. Journal of Family Practice

79. Journal of Family Psychology

80. Journal of General Management

81. Journal of Human Relation

82. Journal of Inerpcrsonal Volence
83. Journal of Marital and Fmily Therapy

84. Journal of Marriage and the Family

85. Journal of Mother and Child

86. Journal of Nonverbal Behavior

87. Journal of Occupational Psychology

88. Journal of Paediatrics, Obstetrics and

89. Journal of Personality and Social Psychology

90. Journal of Psychosomatic Research

91. Journal of Psychotherapy Psychosomatic

92. Journal of Reading Behavior

93. Journal of Science and Technology

94. Journal of Scientific American

95. Journal of Sex Education \& Therapy

96. Journal of Sex Research

97. Journal of Social and Clinical Psychology

98. Journal of Social and Personal Relationship

99. Journal of Social lssues

100. Journal of Social Psychology

101. Journal of Sociology

102. Journal of Sport Psychology

103. Journal of the American Academy of Child...

104. Journal of Vocational Behavior

105. Journal of Youth and Adolescence

106. Jurnat Psikologi Malaysia

107. Language and Cognitive Process

t08. Leadership and Organizational Developmentat Journal

t 09. Leadership Quarterly

110. Management Science

111. Motivation and Emotion

112. Omega-Journal of Death and Dying

113. Organization Studies

1 14. Peabody for Journal of Education

115. Peace and Change

116. Perception and Psychophisics

117. Personality \& Social Psychological Bulletin

118. Personality \& Social Psychological Review

119. Phenomenology + Pedagogy

120. Philippine Journal of Psychology

121. Phillipine Journal of Industrial Relation

122. Philosophy \& Literature

123. Policy

124. Psychological Bulletin

125. Psychological Review

126. Psychological Science

127. Psychology Today

128. Psychonomic Bulletin \& Review

129. Psychopharmacology Bulletin

130. Psychos omatics

131. Psychotherapy and Psychosomatics Journal

132. Psychotherapy and Psychosomatics Review

133. Reading Research Quartely

t34. Scientific Amcrican

135. Sex Roles

136. Sloan Management Review

137. Small Group Research

138. Social Facilitation Science

139. The Annals

140. The Arithmetic Teacher

141. The Journal of Family Practice

142. The Journal of Genetic Psychology

143. The Journal of Sex Research

144. The Journal of Social Psychology

145. The psychologist

146. Transcultural Psychiatric Research Review

147. Work and Occupation

148. World Executive Digest

Sumber: Data Primer yang diolah, 2007

Berdasarkan analisis data diperoleh hasil bahwa peringkat tertinggi pemanfatan jurnal terbitan luar negeri ada pada Journal of Personality and Social Psychology yang menerima sitiran sebesar 68 sitiran $(17,17 \%)$. Tingginya pemanfaatan jurnal tersebut 
didukung oleh kondisi riil di perpustakaan, bahwa Journal of Personality and Social Psychology telah dilanggan sejak tahun 1977 sampai sekarang tanpa pernah berhenti (lihat tabel 1).

Sebaliknya pemanfaatan terendah diterima oleh 98 judul jurnal dimana masing-masing hanya mendapat satu kali sitiran $(0,25 \%)$. Jurnal-jurnal tersebut belum pernah sama sekali dilanggan oleh perpustakaan, kecuali dua jurnal yaitu American Psychologist dan Health Psychology. Kedua jurnal tersebut pernah dilanggan dalam periode waktu tertentu, dan pada saat ini sudah tidak dilanggan.

Dari 148 judul jurnal yang telah dimanfaatkan dalam penulisan artikel pada Jurnal Psikologi UGM tahun 1997-2006, ada 14 judul jurnal yang termasuk dalam kategori pernah dilanggan (sudah berhenti maupun masih dilanggan) Perpustakaan Fakultas Psikologi UGM. Hal tersebut menunjukkan bahwa jurnal terbitan luar negeri yang pernah dilanggan Perpustakaan Fakultas Psikologi Universitas Gadjah Mada telah memberikan manfaat atau kontribusi dalam penulisan artikel pada Jurnal Psikologi UGM tahun 1997-2006 sebesar 14 judul $(9,45 \%)$.

Rendahnya kontribusi tersebut (kurang dari $10 \%$ ) disebabkan terbatasnya koleksi jurnal terbitan luar negeri yang dilanggan sampai saat ini. Karena periode melanggan yang terbatas atau hanya dalam periode waktu tertentu, mengakibatkan keterbatasan nomor-nomor jurnal yang dimiliki Perpustakaan Fakultas Psikologi Universitas Gadjah Mada. Kondisi riil ini dikernukakan oleh seorang mahasiswan \$3 yang mengatakan bahwa ia sangat menyayangkan dan kecewa karena adanya beberapa nomor jurnal terbitan luar negeri yang sangat dibutuhkan, tetapi sudah tidak dilanggan. Berikut petikan wawancaranya:

"Seingat saya dulu waktu kuliah S1 dan S2 di sini, kalau gak keliru perpustakaan sini melanggan Psychological Bulletin. Untuk saat ini saya butuh jurnal tersebut, tapi kok sayangnya sudah tidak dilanggan lagi, padahal harapan saya satusatunya ada di perpustakaan ini"

Sebaliknya pemanfaatan jurnal terbitan luar negeri yang belum pernah dilanggan Perpustakaan Fakultas Psikologi Universitas Gadjah Mada lebih tinggi yaitu sebesar 134 jurnal $(90,55 \%)$. Kondisi ini diperkuat dengan pernyataan pengguna bahwa jurnal yang dibutuhkan, tidak dilanggan oleh Perpustakaan Fakultas Psikologi Universitas Gadjah Mada. Petikan wawancaranya sebagai berikut:

"Saya butuh jurnal-jurnal tentang perkawinan dan keluarga untuk keperluan penulisan disertasi saya, tapi di sini tidak melanggan

Keluhan yang hampir sama juga dikemukakan oleh seorang mahasiswa S1, yang mengatakan bahwa dalam proses penyusunan skripsinya selama ini, ada satu kendala yang menghambat yaitu kesulitan memperoleh jurnal tentang keluarga.

Rincian selengkapnya mengenai frekuensi dan persentase pemanfaatan ke-14 jurnal tersebut dapat dilihat pada tabel 2 .

Berdasarkan analisis data diperoleh hasil bahwa peringkat pertama diduduki oleh Journal of Personality and Social Psychology dengan frekuensi sitiran tertinggi sebesar 68 sitiran atau $39,76 \%$. Tingginya sitiran yang diperoleh JPSP didukung oleh kondisi riil di Perpustakaan Fakultas Psikologi Universitas Gadjah Mada bahwa pengadaan Journal of Personality and Social Psychology yang telah dilanggan sejak tahun 1977 sampai sekarang tanpa pernah berhenti, benar-benar telah membantu pengguna dalam penulisan karya ilmiah mereka.

Di samping itu tingginya frekuensi sitiran yang diperoleh Journal of Personality and Social Psychology didukung pula oleh relevansi atau kesesuaian antara kajian dalam Journal of 
Tabel 2

Frekuensi Pemanfaatan Jurnal Terbitan Luar Negeri Pernal I Yilanggan dalam Artikel Jurnal Psikologi UGM tahun 1997-2006

\begin{tabular}{|c|c|c|c|}
\hline No. & Judul Jurnal & Frek. Disitir & $\%$ \\
\hline 1. & Joumal of Personality and Soxial Psychology & 68 & 39.76 \\
\hline 2. & Joumal of Consulting and Clinical Psychology & 23 & 13,45 \\
\hline 3. & Joumal of Applied Psychology & 21 & 12,28 \\
\hline 4. & Prycholsgical Bulletin & 11 & 6,43 \\
\hline 5. & Joumal of Abnomal Psychology & 9 & 5,26 \\
\hline 6. & Joumal of Counseling Pswhology & 9 & 5.20 \\
\hline 7. & Joumal of Educational Psychology & 8 & 4,67 \\
\hline 8. & Developmental Psyclology & 7 & 4,09 \\
\hline 9. & Joumal of Ocupational Psychology & 5 & 2,92 \\
\hline 10. & Jounat of Croxs Culural Paydology & 3 & 1,75 \\
\hline 11. & Psycholesgical Review & 3 & 1,75 \\
\hline 12. & Joumal of Experimental Psychol syg: General & 2 & 1,16 \\
\hline 13. & Amenican Psychotogist & 1 & 0.58 \\
\hline \multirow[t]{2}{*}{14.} & Health Prychotogy & I & 0,58 \\
\hline & Jumlah & 171 & $100 \%$ \\
\hline
\end{tabular}

Surnber: Data Primer yang diolah, 2007

Personality and Social Psychology dengan artikel yang menyitir. Hal ini dikemukakan oleh seorang staf pengajar, peneliti dan sekaligus penulis artikel ilmiah, bahwa Journal of Personality and Social Psychology sangat mendukung bidang kajian yang digeluti saat ini dan sesuai dengan topik-topik penelitiannya. Berikut ini adalah pernyataan yang disampaikan kepada peneliti:

"selama ini saya menemukan kajian-kajian tentang emosi lebih banyak pada journal tersebut, yang sangat mendukung fokus penelitian maupun kajian saya selama ini. Jurnal apapun itu kalau topik-topik tersebut ada, ya saya akan pergunakan, sepanjang ada relevansi dengan apa yang saya perlukan".

Interpretasi yang menunjukkan adanya relevansi antara judul artikel dengan rujukan yang dimanfaatkan dapat dilihat pula oleh keahlian beberapa penulis yang andil dalam penyusunan artikel.

Pencermatan lebih jauh ke dalam isi artikel, pemanfaatan judul-judul rujukan menunjukkan bahwa rujukan bermanfaat dalam hal pendekatan teori, dan ada juga yang dipergunakan sebagai pendukung hasil penelitian tersebut. Hal ini sesuai dengan pendapat Garfield dalam Hartinah (2002) bahwa seseorang menyitir karya orang lain karena untuk keperluan pendekatan teori dan memperkuat hasil temuannya.

Sementara itu frekuensi sitiran terendah diperoleh dua jurnal yaitu American Psychologist dan Health Psychology, dimana masing-masing hanya menerima satu kali sitiran $(0,58 \%)$. Hal ini kemungkinan besar disebabkan oleh periode waktu melanggan terbatas (dilanggan hanya dalam periode waktu tertentu). Kondisi riil menunjukkan bahwa kedua jurnal tersebut dilanggan hanya dalam periode waktu tertentu, yaitu American Psychologist (1977-1983) dan Health Psychology (1993-2006).

Kenyataan ini didukung pula oleh pernyataan mahasiswa yang menyayangkan dan kecewa dengan beberapa nomer jurnal yang tidak tersedia di perpustakaan karena sudah tidak dilanggan.

Terlepas dari sesuai atau tidaknya judul artikel dengan judul rujukan, secara riil judul-judul rujukan tersebut tercantum dalam daftar pustaka artikel karya Siti Rohmah Nurhayati dan Sugiyanto, yang berarti bahwa rujukan telah mendukung penulisan artikel tersebut. Hal ini sesuai dengan pendapat yang dikemukakan Soehardjan dan Muhajan (1996:13) bahwa dalam suatu karya tulis, pengutipan suatu pendapat yang berasal dari suatu artikel, wajib mencantumkan nama penulis artikel tersebut, kemudian mencantumkannya dalam daftar pustaka artikel.

Hasil penelitian pemanfaatan jurnal-jurnal terbitan luar negeri yang pernah dilanggan (masih dilanggan maupun sudah berhenti dilanggan oleh Perpustakaan Fakultas Psikologi UGM) dalam penulisan artikel ilmiah Jurnal Psikologi UGM tahun 1997-2006, secara keseluruhan menunjukkan karena adanya relevansi antara artikel dengan kajian-kajian 
yang terdapat dalam jurnal terbitan luar negeri tersebut. Hal ini diperkuat dengan adanya kesesuaian antara judul artikel dengan judul rujukan yang dimanfaatkan. Telaah ke dalam isi artikel diketahui bahwa sebagian besar rujukan-rujukan tersebut cenderung lebih 1 anyak dimanfaatkan dalam hal pendekatan teori dan diskusi hasil penelitian terutama untuk memperkuat hasil temuannya.

Seperti telah dikemukakan pada landasan teori, bahwa kemutakhiran literatur yang dirujuk dalam suatu karya tulis ilmiah mencerminkan kekinian (actuality) informasi dari karya tu lis tersebut (Hermanto, 2002:1). Pada penelitian ini untuk menentukan kemutakhiran Iiteratur jurnal terbitan luar negeri yang disitir dalam artikel ilmiah Jurnal Psikologi UGM tahun 1997-2006, berpedoman pada Instrumen Evaluasi untuk Akreditasi Berkala Ilmiah 2001, yang dikeluarkan oleh Direktorat Pembinaan Penelitian dan Pengabdian pada Masyarakat-Direktorat Jendral Pendidikan Tinggi (2001). Pada pedoman ini salah satu tolok ukur mutu berkala ilmiah (jurnal) adalah kemutakhiran bahan pustaka yang dipergunakan sebagai rujukan, dan kemutakhiran bahan pustaka ini dengan melihat proporsi terbitan sepuluh tahun terakhir.

Berdasarkan pedoman tersebut, hasil analisis terhadap kemutakhiran sitiran menunjukkan bahwa di dalam Jurnal Psikologi UGM tahun 1997-2006, ada 209 sitiran $(52,77 \%)$ termasuk dalam kategori mutak hir, 180 sitiran $(45,47 \%)$ tidak termasuk dalam kategori mutakhir, sedangkan tujuh sitiran (1,76\%) merupakan jurnal terbitan luar negeri yang diterbitkan 30 tahun yang lalu atau lebih (lihat tabel 3 ).

Seperti telah dikemukakan sebelumnya bahwa pemanfaatan jurnal terbitan luar negeri dalam Jurnal Psikologi UGM tahun 1997-2006 lebih banyak disebabkan adanya relevansi atau kesesuaian antara topik yang disitir dengan topik yang menyitir. Dengan demikian tidak menutup kemungkinan bahwa jurnal terbitan luar negeri yang telah diterbitkan 30 tahun yang lalu atau lebih, dapat dimanfaatkan karena ada relevansi dengan topik tulisan. Hal ini sesuai dengan hasil penelitian Hermanto (2004:3), bahwa kemutakhiran sitiran tidak mempengaruhi kualitas tulisan atau penelitian seseorang sepanjang masih ada relevansi di antara keduanya.

Tabel 3

Usia Jurnal terbitan Luar Negeri yang Dimanfaatkan dalam Jurnal Psikologi UGM 1997-2006

\begin{tabular}{|c|c|c|}
\hline Usia (tahun) & Jumlah & Persentase (\%) \\
\hline $0-2$ & 40 & 10,10 \\
\hline $3-4$ & 59 & 14,89 \\
\hline $5-6$ & 47 & 11,86 \\
\hline $7-8$ & 31 & 7,82 \\
\hline $9-10$ & 32 & 8,08 \\
\hline $11-15$ & 77 & 19,44 \\
\hline $16-20$ & 55 & 13,88 \\
\hline $21-25$ & 34 & 8,58 \\
\hline $26-30$ & 14 & 3,53 \\
\hline$>30$ & 7 & 1,76 \\
\hline Jumlah & 396 & $100 \%$ \\
\hline
\end{tabular}

Dikemukakan pula oleh Hermanto (2004:3) bahwa pada kajian terhadap topik-topik tertentu yang tidak diminati, menyebabkan seorang peneliti kesulitan memperoleh rujukan terbaru, sehingga rujukan lama dapat dimanfaatkan karena belum ada literatur baru yang lebih baik atau lebih lengkap dari literatur tersebut. Juga dikemukakan oleh Mikkailov (dalam Herlina, 1995:36), bahwa penggunaan literatur yang relatif tua tahun terbitannya dapat pula dikarenakan adanya kekhususan informasi, misalnya mengenai publikasi orisinil yang menjadi syarat konsep, ide, atau metodologi.

\section{PENUTUP}

\section{A. Simpulan}

Berdasarkan hasil penelitian diperoleh beberapa simpulan sebagai berikut:

1. Di dalam Jurnal Psikologi UGM terbitan tahun 1997-2006, telah dimanfaatkan jurnal terbitan Juar 
negeri sebanyak 148 judul (judul-judul jurnal secara lengkap dapat dilihat pada tabel 1).

2. Persentase pemanfaatan jurnal terbitan luar negeri pada Jurnal Psikologi UGM terbitan tahun 1997 2006, peringkat pertama diperoleh Journal of Personality and Social Psychology dengan perolehan sitiran sebanyak 68 sitiran $(17,17 \%)$. Sedangkan rangking terendah diterima oleh 98 jurnal, dimana masing-masing memperoleh satu kali sitiran $(0,25 \%)$.

Sementara itu, di antara 148 judul jurnal tersebut ada $14(9,45 \%)$ jurnal terbitan luar negeri yang pernah dilanggan (sudah berhenti maupun masih dilanggan) oleh Perpustakaan Fakultas Psikologi UGM.

Setelah dirangking berdasarkan kelompok jurnal terbitan luar negeri yang pernah dilanggan (sudah berhenti maupun masih dilanggan) oleh Perpustakaan Fakultas Psikologi UGM, peringkat pertama diperoleh Journal of Personality and Social Psychology $(39,76 \%)$, Journal of Consulting and Clinical Psychology $(13,45)$, Journal of Applied Psychology (12,28\%), Psychological Bulletin $(6,43 \%)$, Journal of Abnormal Psychology dan Journal of Counseling Psychology masing-masing (5,26\%), Journal of Educational Psychology (4,67\%), Developmental Psychology (4,09\%), Journal of Occupational Psychology (2,92\%), Journal of Cross-Cultural Psychology dan Psychological Review masing-masing (1,75\%), Journal of Experimental Psychology: General (1,16\%), American Psychologist dan Health Psychology masing-masing (0,58\%).

3. Ada kecenderungan bahwa keempatbelas jurnal tersebut memiliki relevansi dengan topik-topik artikel ilmiah yang dimuat pada Jurnal Psikologi
UGM tahun 1997-2006. Jurnal-jurnal terbitan luar negeri yang disitir lebih banyak dimanfaatkan dalam hal pendekatan teori dan diskusi hasil penelitian terutama untuk memperkuat hasil temuannya.

4. Secara deskriptif hasil penelitian menunjukkan bahwa kemutakhiran jurnal terbitan luar negeri yang telah dimanfaatkan dalam Jurnal Psikologi UGM 1997-2006, adalah 52,77\% termasuk dalam kategori mutakhir, 45,47\% tidak termasuk dalam kategori mutakhir. Di samping itu ada $1,76 \%$ jurnal terbitan luar negeri yang diterbitkan 30 tahun yang lalu atau lebih, meskipun demikian pemanfaatan jurnal tersebut dapat dimaklumi karena (1) adanya relevansi antara topik yang disitir dengan yang menyitir, (2) karena kelangkaan topik penelitian, (3) karena adanya kekhususan informasi.

\section{B. Saran}

Berdasarkan hasil penelitian yang telah dilakukan, ada beberapa hal yang peneliti sarankan.

1. Perlu mempertahankan keberlanjutan pengadaan jurnal terbitan luar negeri yang telah memenuhi kebutuhan pengguna, seperti pada tabel berikut.

Tabel 4

Daftar Jurnal Terbitan Luar Negeri yang dapat Dipertahankan untuk Tetap Dilanggan

\begin{tabular}{|l|l|}
\hline No. & \multicolumn{1}{|c|}{ Judul Jurnal } \\
\hline 1. & Journal of Personality and Social Psychology \\
\hline 2. & Joumal of Consulting and Clinical Psychology \\
\hline 3. & Joumal of Applied Psychology \\
\hline 4. & Psychological Bulletin \\
\hline 5. & Journal of Abnomal Psychology \\
\hline 6. & Journal of Counseling Psychology \\
\hline 7. & Journal of Educational Psychology \\
\hline 8. & Developmental Psychology \\
\hline 9. & Journal of Occupational Psychology \\
\hline 10. & Journal of Cross Cultural Psychology \\
\hline 11. & Psychological Review \\
\hline 12. & Journal of Experimental Psychology: General \\
\hline 13. & American Psychologist \\
\hline 14. & Health Psychology \\
\hline
\end{tabular}

Sumber: Data Primer yang diolah, 2007 
2. Masih rendahnya kategori jurnal yang pernah dilanggan (sudah berhenti maupun masih dilanggan) oleh Perpustakaan Fakultas Psikologi UGM yang dimanfaatkan dalam penulisan artikel pada Jurnal Psikologi UGM tahun 1997-2006, yaitu sebesar 9,45\% (kurang dari sepuluh persen), mengindikasikan bahwa perpustakaan perlu menambah pengadaan jurnal terbitan luar negeri utamanya yang benar-benar diperlukan oleh pengguna. Beberapa jurnal yang termasuk dalam kategori sepuluh besar namun belum dilanggan oleh Perpustakaan Fakultas Psikologi UGM adalah: Sex Roles, Aggressive Behavior, Personality \& Social Psychological Bulletin, The Journal of Social Psychology, Academy of Management Journal, Death Studies, Human Relations, dan Motivation and Emotion.

3. Dalam penentuan kebijakan pengadaan maupun penghentian jurnal terbitan luar negeri yang dilanggan, perlu memperhatikan kebutuhan pengguna.

4. Disarankan kepada Unit Publikasi Fakultas Psikologi UGM untuk lebih selektif dalam mempublikasikan artikel ilmiah ke dalam Jurnal Psikologi UGM terbitan selanjutnya, utamanya dalam hal kemutakhiran sitiran. Karena hasil penelitian ini menunjukkan bahwa hanya $52,77 \%$ sitiran yang termasuk dalam kategori mutakhir. Sementara untuk memperoleh nilai akreditasi yang lebih tinggi, diperlukan minjmal $80 \%$ sitiran masuk dalam kategori mutakhir

5. Perlu dilakukan kajian yang lebih luas (tidak terbatas pada Jurnal Psikologi UGM tahun 19972006), tetapi juga terhadap skripsi, tesis, disertasi dan publikasi ilmiah yang merupakan produk Fakultas Psikologi UGM, sehing a diperoleh hasil yang lebih akurat untuk penentuan pengadaan jurnal terbitan luar negeri yang a kan dilanggan.

\section{DAFTAR PUSTAKA}

Andriani, J. 2002. "Studi Kualitatif mengenai Alasan Menyitir Dokumen: Kasus pada Lima Mahasiswa Program Pascasarjana IPB". Dalam Jurnal Perpustakaan Pertanian, Vol. 11, (2):2940.

Arikunto, S. 2006. Prosedur Penelitian Suatu Pendekatan Praktik. Jakarta: PT Rineka Cipta.

Azwar, S. 1998. Metode Penelitian. Yogyakarta: Pustaka Pelajar.

Budd, J.M. 1990. "Higher Educaton Literature: Characteristic of Citation Patterns". Dalam The Journal of Higher Education. 61 (1):84 $-97$.

Direktorat Pembinaan Penelitian dan Pengabdian pada Masyarakat-Ditjen Dikti bekerja sama dengan Lembaga Ilmu Pengetahuan Indonesia, Ikatan Penyunting Indonesia, \& Kantor Menteri Negara Riset dan Teknologu. 2001. Instrumen Evaluasi untuk Akreditasi Berkala Ilmiah (Lampiran). Jakarta.

Evans, G.E. and Zarnosky, M.R. 2000. Developing Library and Information Center Collections. $4^{\text {th }}$ ed. Colorado: Libraries Unlimited.

Fakultas Psikologi UGM. 1999. Buku Pedoman Fakultas Psikologi UGM. Yogyakarta: Fakultas Psikologi UGM.

Hadi, S. 1975. Statistik Jilid II. Yogyakarta: Yayasan Penerbitan Fakultas Psychologi Universitas Gadjah Mada.

Harjono, H. 2006. "Hasil Penelitian LIPI tak Banyak Diketahui Umum". Dalam http:// www.lipi.go.id. (Diakses 29 September 2006). 
Hartinah, S. 2002. "Analisis Sitiran (Citation Analysis)". Dalam Kumpulan Makalah Kursus Bibliometrika. Depok: Masyarakat Infometrika Indonesia.

Herlina, E. 1995. "Analisis Sitiran Publikasi Hasil Penelitian Pertanian". Dalam Jurnal Perpustakaan Pertanian, Vol. IV (2):33-38.

Hermanto. 2004. "Kajian Kemutakhiran Referensi Artikel Ilmiah pada Beberapa Jurnal Ilmiah Penelitian Pertanian" Dalam Jurnal Perpustakaan Pertanian Vol. 13 (1):1-6.

Holmes, A. and C.Oppenheim. 2001. "Use of Citation Analysis to predict the Ourcome of the 2001 Research Assessment Exercise for Unit of Assessment (UoA) 61: Library and Information Management". Dalam Information Research. Vol. 6, No. 2.

Irwanto. 2004. Panduan Membuat Proposal Penelitian. Jakarta: Lembaga Penelitian Universitas Katolik Indonesia Atma Jaya.

Kamus Besar Bahasa Indonesia. 1988. Jakarta: Balai Pustaka.

Kerlinger, F.N. 1990. Asas-asas Penelitian Behavioral. Edisi 3. Penerjemah: Landung R. Simatupang. Yogyakarta: Gadjah Mada University Press.

Koentjaraningrat dan Fuad Hasan (Ed.). 1994. Metode-metode Penelitian Masyarakat. Jakarta: Gramedia Pustaka Utama.

Kurniawan, K. 2005. "Mengapa Publikasi Ilmiah Kita Rendah?"'Dalam Pikiran Rakyat, 5 Oktober.

Lasa HS. 1998. Kamus Istilah Perpustakaan. Yogyakarta: Gadjah Mada University Press. Lembaga Ilmu Pengetahuan Indonesia (LIPI). 1983. Keputusan Ketua LIPI No. 81/Kep/H.10/
1983 tentang tata tertib publikasi. Jakarta: LIPI

Prawitasari, J.E. 2005. "Psikologi Nusantara: Ke Manakah Kita Menuju?" Pidato Lustrum VIII Fakultas Psikologi UGM. Yogyakarta: Fakultas Psikologi UGM

Rousseau, R. 2002. "Journal Evaluation: Technical and Practical Issues". Dalam Library Trends. Vol. 50, Winter (3):418-439.

Saleh, A.R. \& Toha, Y.Y. 1996. Pengelolaan Terbitan Berseri. Jakarta: Universitas Terbuka.

Septiyantono, T. 1997. "Kajian Bibliometrika: Manfaat bagi Ilmu Perpustakaan" Disampaikan dalam Seminar di UPT Perputakaan UGM tanggal 9 Agustus 1997.

2003. Dasar-dasar Ilmu

Perpustakaan dan Informasi. Yogyakarta: Jurusan Ilmu Perpustakaan dan Informasi Fakultas Adab IAIN Sunan Kalijaga.

Soehardjan, M. dan Sundari, T.S. 1995. Data Rujukan sebagai Indikator Dampak Artikel. Jurnal Perpustakaan Pertanian. Vol. IV, (2):39-42. Soehardjan, M. dan Zakiah M. 1996. "Pemikiran tentang Cara Merujuk Nama Orang Indonesia dalam Artikel Ilmiah". Dalam Jurnal Perpustakaan Pertanian. Vol. V, (1):13-16. Sujana, J.G. 2006. "Mengoptimumkan Pengembangan Koleksi”. Dalam Buletin Perpustakaan dan Informasi Bogor. Edisi 3 Oktober. Dalam http://bpib-art.blogspot.com (Diakses 14 Februari 2007).

Sulistyo-Basuki. 1994. "Analisis Sitiran, Kositiran dan Pasangan Bibliografis (Citation Analysis, CoCitation, dan Bibliographic Coupling)". Dalam Sosok Pribadi Unik Mastini Hardjoprakosa. Mochtar, K. dkk (Ed). Jakarta: Yayasan Kawedi. 
2002. "Bibliometrika,

Sainsmetrika dan Informetrika”. Dalam

Kumpulan Makalah Kursus Bibliometrika.

Depok: Masyarakat Infometrika Indonesia.

Suryabrata, S. 2003. Metodologi Penelitian. Jakarta:

RajaGrafindo Persada

Sylvia, M.J. 1998. "Citation Analysis as an

Unobstrusive Method for Journal Collection

Evaluation Using Psychology Student

Research Bibliographies". Collection

Building. Bradford. Vol. 17, (1):20. Dalam

http://proquest. umi.com. (Diakses 26

Desember 2006).

Wikipedia, The Free Encyclopedia. Dalam (http:// en.wikipedia.org/wiki/Editorial board).

Diakses 23 Mei 2007, pukul 11.00.

Wojowasito, S. dan Tito W. 1980. Kamus lengkap

Inggris-Indonesia, Indonesia-Inggris.

Bandung: Hasta.

Yulia, Y. 1995. "Karakteristik Literatur yang Disitir dalam Disertasi Bidang Agronomi Tahun 1981-1990". (Tesis). Depok: Program Pascasarjana Universitas Indonesia.

Zulaikha, S.R. 2002. "Kajian Analisis Sitasi terhadap Skripsi Mahasiswa IAIN Sunan Kalijaga di UPT Perpustakaan IAIN Sunan Kalijaga Yogyakarta (Suatu Evaluasi Keterpakaian Koleksi Perpustakaan Ditinjau dari Analisis Sitasi)". (Tesis). Yogyakarta: Program Pascasarjana Universitas Gadjah Mada. 